\title{
Application of Super Capacitor in HEV Regenerative Braking System
}

\author{
Haoming Zhang ${ }^{*}$, , Yinghai Wang ${ }^{2}$ and Peh Lian Soon ${ }^{3}$ \\ ${ }^{1}$ Department of Electrical and Information Engineering, Tongling University, Tongling, 214000, China \\ ${ }^{2}$ School of Electrical and Information Engineering, SIPIVT, 215321, Suzhou, China \\ ${ }^{3}$ Shining Sunshines Global Pte Ltd, Singapore
}

\begin{abstract}
In order to ensure superiority of fuel and improve start and stop performance of hybrid electric vehicle, battery is used in the system. Limited by vehicle's size, traditional hybrid electric vehicles can only carry a limited number of batteries, resulting in a relatively short running distance in one battery charge cycle. To improve energy using efficiency and increase vehicle safety, composite power based on lithium ion battery and super capacitor is proposed in this paper. Super capacitor parameter is designed according to hybrid electric vehicle regenerative braking model based on Matlab simulation. The experiment is also evaluated based on the composite power. Results show that both motor and power can work well and super capacitor can absorb the regenerative braking energy of hybrid electric vehicle greatly.
\end{abstract}

Keywords: Capacitor, composite power, super hybrid electric vehicle.

\section{INTRODUCTION}

In order to meet the developmental needs of the modern society, today's vehicle is moving towards the concept of energy saving, environmental protection and security. In our country, in terms of energy status, development of a new generation of energy-saving and environment-friendly vehicle is very important, which means that automotive industry could get rid of excessive dependence on petroleum to a great extent and can realize the diversification of vehicle energy; Develop HEV (Hybrid Electric Vehicle) is one of the best paths to solve this problem [1-3] but battery capacity, system utilization efficiency and other aspects lead to a short electric mileage, which has limited its development.

Although of low battery capacity, low efficiency of the system and low efficiency of driving lead the HEV to a short mileage, frequent brake and inability of brake energy to recover under complex city conditions is also one of the important reasons. After research and analysis, it is found that energy used for friction brake is about $30 \%$ of the total. Therefore, the rational use of electric brake instead of friction brake, not only provides an auxiliary brake function for $\mathrm{HEV}$, which can improve vehicle braking performance and increase safety of vehicle, but also can save energy through regenerative brake. The recovered energy can further be absorbed by the battery and can extend HEV running distance.

In the traditional regenerative braking system, the commonly used part in the system is the battery, which can be charged by feedback regenerative braking energy. Its principle is shown in Fig. (1).

*Address correspondence to this author at the Department of Electrical and Information Engineering, Tongling University, Cuihu Road, Tongling, 214000, China; Tel: 13013801792; E-mail: zhm20060616@163.com
Although HEV regenerative braking technology based on battery has rapidly developed in recent years, battery technology still hampers the development of high efficiency HEV brake regeneration technology [4-6]. The existing problems are mainly as follows:

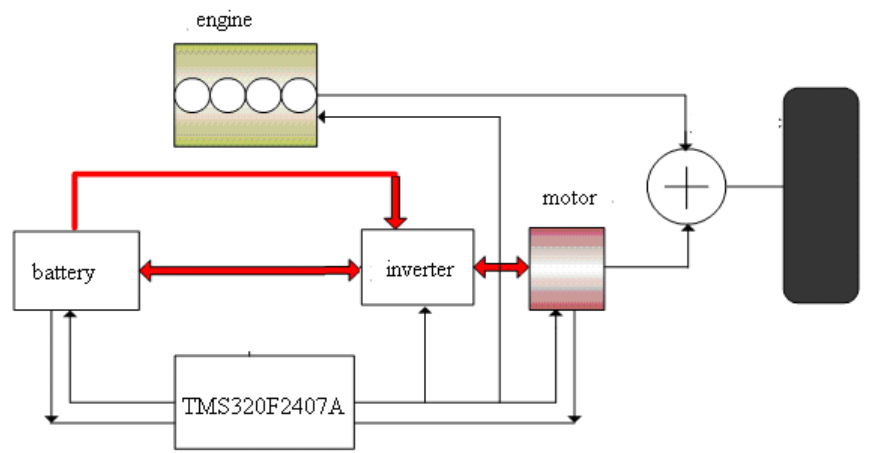

Fig. (1). Illustration of HEV with battery.

1) Low power density: limited by the discharging ratio of battery, the battery only can charge and discharge with a small current under frequent HEV braking status. Thus, battery used in the system must absorb the regenerative braking energy in a short time which means that the battery must be charged by high level current. This however conflicts with battery's inner charging characteristics and renders the battery unable to meet the requirement of the vehicle's dynamic performance. If the battery is forced to be charged with a large current for a long time, it is bound to cause damage to the battery, which can seriously affect the life of the battery. If the number of battery is increased for absorbing the braking energy, it is bound to increase the complexity of battery management, in turn increasing the cost of vehicle. 
2) Limited charge cycle: The vehicle's frequent acceleration and deceleration in complicated working condition increase charging and discharging time of the battery, which in turn reduces the charge cycle of the battery affecting its performance.

3) Poor low temperature performance: Under low temperature, the battery cannot fully absorb the regenerative braking energy and is unable to achieve the goal of increasing HEV running distance.

According to the situation, a new regenerative braking based on composite power supply is proposed in the paper, which not only can meet the HEV power system energy requirements but also can effectively absorb HEV regenerative braking energy increasing HEV electric driving distance.

\section{NEW HEV DRIVE SYSTEM BASED ON COMPOSITE POWER SUPPLY}

Fig. (2) shows a new type of HEV drive system powered by lithium ion battery and super capacitor [7-11]. In order to increase the calculation capability of the system, TMS320F2812 is used in the system instead of TMS320LF2407A as the controller core which is a famous DSP produced by TI Company. The DSP accepts the sensor signal and then determines the starting, acceleration, deceleration and brake of the vehicle. At the starting point, the system requires big acceleration, using the special characteristic of super capacitor which causes the supply of a large current in a very short time, due to which the controller can drive the motor in a high speed quickly; if the vehicle runs with engine in high pollution area, and controller turns off the engine, high power density lithium ion battery will begin to work, providing energy for the motor so that it can make the vehicle running; In high speed area, if the battery cannot supply the energy that the vehicle needs, the engine will turn on again and battery and super capacitor will also begin to work enabling the engine and motor to supply composite torque in order to drive the vehicle; When the vehicle is in a need to brake, the motor begins to work in the state of generator and feedback energy is changed to electric power letting the super capacitor absorb it in a short time. This method can greatly improve the utilization rate of energy storage.

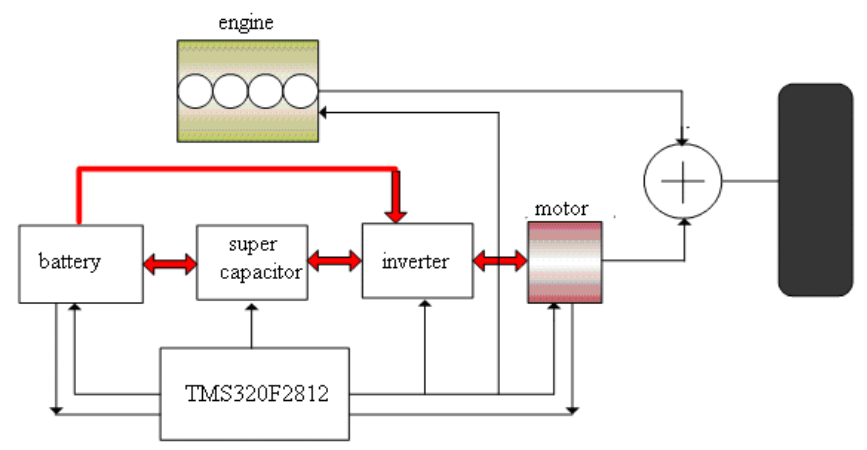

Fig. (2). Illustration of HEV with composite power.

In the system, super capacitor not only supplies energy to boost the engine torque, making the system work in a high efficiency, outputting a larger power, obviously reducing exhaust emissions and noise but also can absorb energy from braking which can further reduce vehicle's energy consumption. It can be said that in the system, the super capacitor plays a very important role and its performance and parameters are directly related to the performance of the final system.

\section{STUDY ON THE BRAKING MODEL OF HEV}

\subsection{Dynamic Model of HEV}

When a vehicle runs on a road, it overcomes the rolling resistance of tire from the ground and air resistance formed by the interaction between the body and the air. When the vehicle is in a slope, it also overcomes the slope component of gravity, which is called the slope resistance. When the vehicle is on acceleration in a line, it must overcome the inertia force of the car itself, which is called accelerated resistance. Therefore, the total resistance of the vehicle in running can be expressed as formula 1 :

$\Sigma F=F_{f}+F_{w}+F_{i}+F_{j}$

In formula 1: $F_{f}$, rolling resistance; $F_{w}$, air resistance; $F_{i}$, slope resistance; $F_{j}$, accelerated resistance; In formula 1 , rolling resistance and air resistance may exist in any driving condition while slope resistance and acceleration resistance only exist in some special conditions.

\subsection{HVE Braking Model}

Hypothesis: the resistance of HEV movement is $f$, and the regenerative braking energy for recyclable can be expressed as formula 2 :

$E=\frac{1}{2} m V_{1}^{2}-\frac{1}{2} m V_{2}^{2}-f * s$

In formula 2: E, Recyclable energy $(J) ; V_{1}$, initial speed of vehicle ( $m / s) ; V_{2}$, the final speed of vehicle; $s$, braking distance $(\mathrm{m})$; f, vehicle driving resistance $(\mathrm{N})$.

According to the vehicle motion equation:

$m \ddot{x}=(-B-f)$

In formula $3: \ddot{x}$, the vehicle acceleration $\left(m / s^{2}\right) ; \mathrm{B}$, braking force $(\mathrm{N})$;

The vehicle running characteristics are shown in Fig. (3).

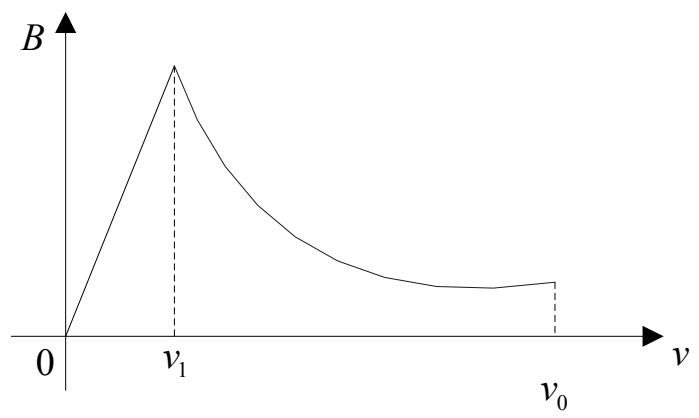

Fig. (3). Characteristic of vehicle running. 
Assuming the vehicle brakes at an even road, when the vehicle is running in the stage from $V_{0}$ to $V_{1}$, its motion equation can be expressed as follows:

$m \ddot{x}=\left(-\frac{P}{\dot{x}}-G f-\frac{C_{D} A \dot{x}^{2}}{21.25}\right)$

Assuming that the automobile accelerates on an even road, when the vehicle is running in the stage from $V_{1}$ to stop, its motion equation can be expressed as follows:

$m \ddot{x}=\left(-K \dot{x}-G f-\frac{C_{D} A \dot{x}^{2}}{21.25}\right)$

Accordingly, HEV dynamics model is obtained as follows:

$$
\begin{aligned}
& m \ddot{x}=-\frac{P}{\dot{x}}-G f-\frac{C_{D} A \dot{x}^{2}}{21.25}(V 1 \sim V 0) \\
& m \ddot{x}=-K x-G f-\frac{C_{D} A \dot{x}^{2}}{21.25}(V 1 \sim 0)
\end{aligned}
$$

\subsection{The Recovery Energy in HEV Braking}

According to the hybrid electric vehicle braking, dynamic model is expressed in formula 6. MATLAB is used to establish the braking model as shown in Fig. (4).

For making a simulation, parameters of $\mathrm{HEV}$ are as follows: braking power $P_{\max }=45 \mathrm{KW}$, vehicle quality $m=3000 \mathrm{~kg}$, rolling resistance $f=0.010$, air resistance coefficient $C_{d}=0.35$, windward area $A=2.8 \mathrm{~m}^{2}$, rolling radius $0.250 \mathrm{~m}$; vehicles drive ratio: 4.63 .

From calculation, HEV braking characteristics obtained are shown in Table $\mathbf{1}$

\section{SUPER CAPACITOR PARAMETERS BASED ON REGENERATIVE BRAKING}

In order to absorb the maximization braking energy, hypothesis of the process of absorption proposes that the battery at an optimal state can absorb a part of feedback energy, and super capacitor in an energy deficiency state can absorb most of the braking energy regeneration by motor, accounting for about $80 \%$ of the total energy.

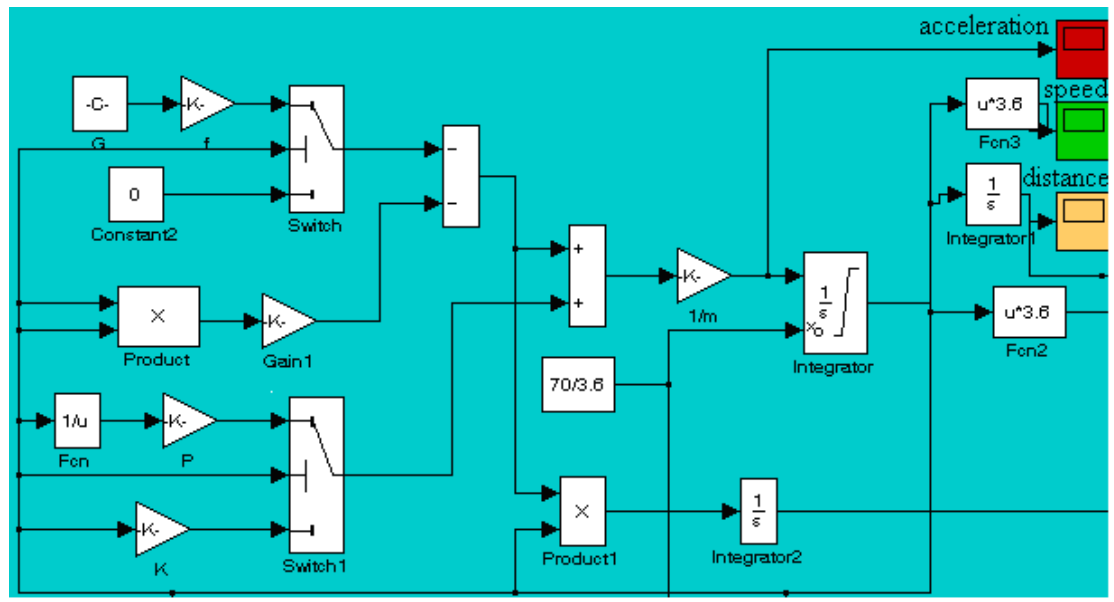

Fig. (4). Model of HEV braking based on matlab.

Table 1. Characteristic list 1 of HEV braking.

\begin{tabular}{|c|c|c|c|c|}
\hline Speed $(\mathbf{k m} / \mathbf{h})$ & Braking Time (s) & Braking Distance (m) & Total Energy (J) & Recovery Energy (J) \\
\hline \hline 30 & 17.26 & 38.23 & 104200 & 92150 \\
\hline 40 & 18.92 & 54.7 & 185200 & 166800 \\
\hline 50 & 20.88 & 80.28 & 289400 & 259400 \\
\hline 60 & 23.38 & 117 & 416700 & 367400 \\
\hline 70 & 26.06 & 165.5 & 567100 & 488100 \\
\hline 80 & 28.95 & 225.8 & 937500 & 618200 \\
\hline 90 & 31.99 & 297.4 & 1157000 & 745600 \\
\hline 100 & 35.09 & 379.3 & 1400000 & 894300 \\
\hline 110 & 38.21 & 470.3 & 1667000 & 1035000 \\
\hline 120 & 41.29 & 568.7 & 1373000 \\
\hline
\end{tabular}


According to the characteristics of super capacitor, its energy storage can be expressed as:

$E=\frac{1}{2} C\left(U_{1}^{2}-U_{2}^{2}\right)$

In formula 7: $E$, super capacitor energy storage(J); C, super capacitor capacity( F); $U_{1}$, voltage of super capacitor after charging $(\mathrm{V}) ; U_{2}$, voltage of super capacitor before charging $(\mathrm{V})$.

According to formula 7:

$C=\frac{2 E}{U_{1}^{2}-U_{2}^{2}}$

The values of the super capacitor parameters can be assumed as follows:

$S O C \approx 0.5, U_{2}=75 \mathrm{~V}, U_{1}=150 \mathrm{~V}$.

From calculation, the reference of super capacitor capacitance is shown in Table 2.

Table 2. Capacitance list of super capacitor.

\begin{tabular}{|c|c|c|}
\hline Braking Speed (km/h) & Absorb Energy (J) & Capacitor Capacity (F) \\
\hline \hline 30 & 73720 & 8.7372 \\
\hline 40 & 133440 & 15.8151 \\
\hline 50 & 207520 & 24.5950 \\
\hline 60 & 293920 & 34.8350 \\
\hline 70 & 390480 & 46.2791 \\
\hline 80 & 494560 & 58.6145 \\
\hline 90 & 596480 & 70.6939 \\
\hline 100 & 715440 & 84.7929 \\
\hline 110 & 828000 & 98.1333 \\
\hline 120 & 1018400 & 120.6993 \\
\hline
\end{tabular}

\section{EXPERIMENT}

According to design, composite power supply based on super capacitor and lithium ion battery supply energy to fulfill digital HEV driving system and the test platform is shown in Fig. (5).

Fig. (6) presents waveforms of three-phase motor current. As can be seen from the graph, both the amplitude and position of three phase current are constant, which means that the motor can work well and the energy system can display a good performance.

In energy test experiment, let lithium ion battery and super capacitor supply energy to permanent magnet synchronous motor respectively. Fig. (7) shows the current waveform when the super capacitor instead of lithium ion supplies the energy to the battery in a short time. As can be seen from the graph, in the moment of energy switching, motor current almost shows no change. This therefore fully meets the requirements of HEV.

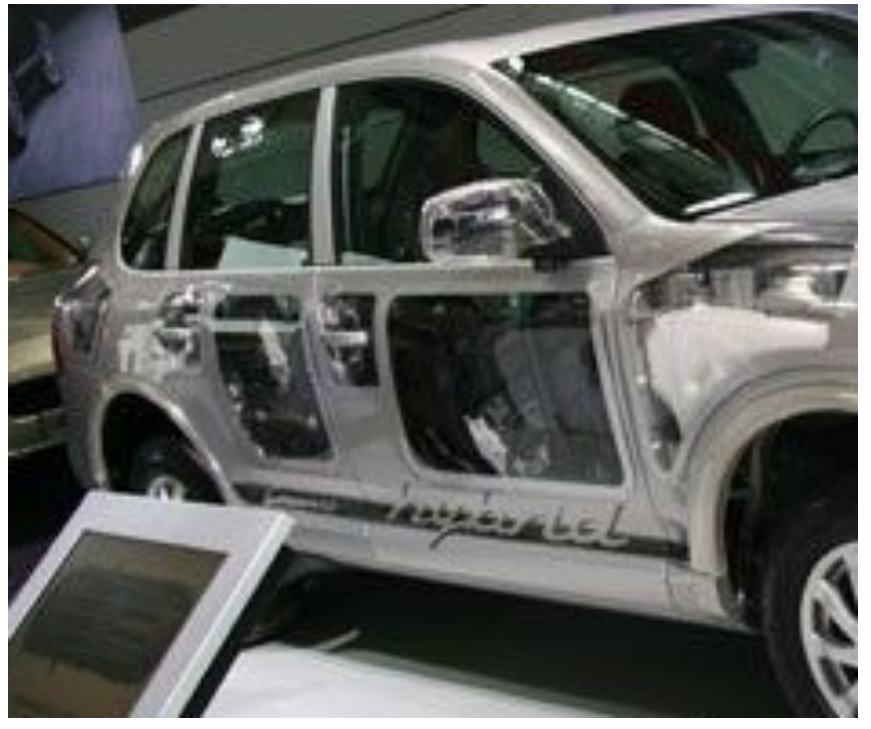

Fig. (5). HEV test platform.

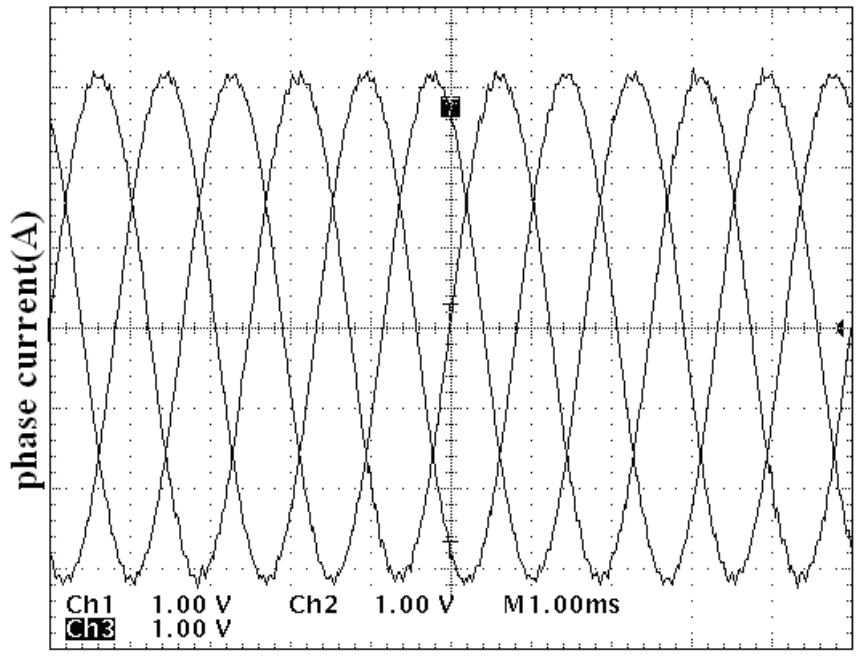

Fig. (6). Three phase current waveforms.

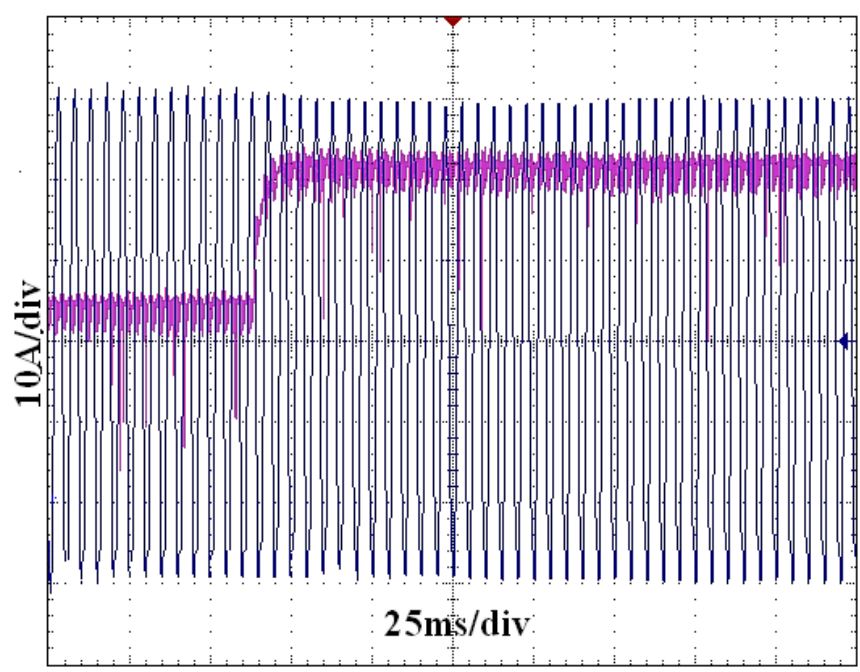

Fig. (7). Waveform of inverter voltage based on super capacitor electric power supply.

Fig. (8) shows the relationship between capacitor voltage and motor speed in acceleration. As can be seen from the 
graph, when motor speed needs to increase in a short time, super capacitor supplies a large instantaneous transient power and with the help of capacitor, the vehicle gets a very large acceleration, getting rid of the excessive demand of engine and reducing emissions of pollutants.

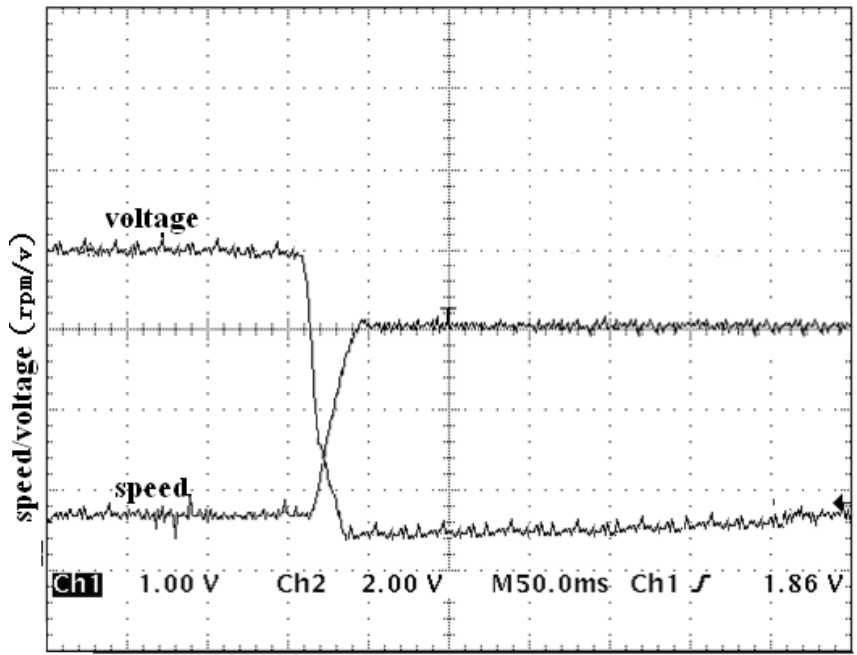

Fig. (8). Voltage waveform of super capacitor.

Fig. (9) shows the relationship between super capacitor voltage and motor speed in deceleration. As can be seen from the graph, when motor speed is in a need to decrease in a short time, super capacitor absorbs a large instantaneous transient power. When the super capacitor voltage is close to protection upper limit, TMS320f2812 cuts off the BUCK control signal and at the same time, opens up pumping circuit in order to protect the DC bus. With the help of the capacitor, the vehicle releases large amounts of energy, not only getting rid of the excessive demand for battery and reducing the amount of harm to the battery, but also reducing the effect of braking distance on deceleration, in turn increasing the safety of the vehicle.

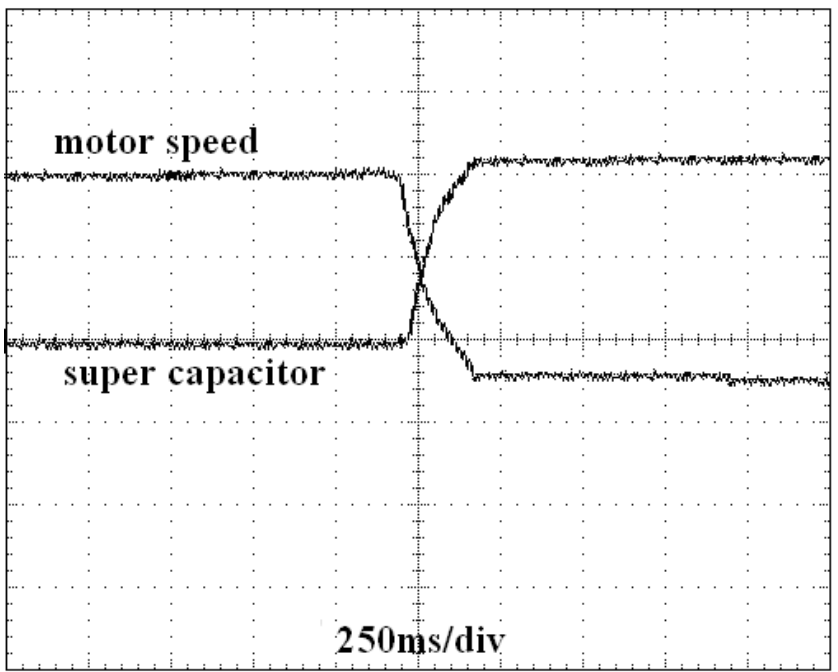

Fig. (9). Voltage waveform of super capacitor.

In the stage of energy feedback, the super capacitor is charged by a large current through the buck circuit. Waveforms of charging current are shown in Fig. (10). As can be seen from the graph, the charging current is about
$10 \mathrm{~A}$, current value is constant, and the pulse of the current is also very small.

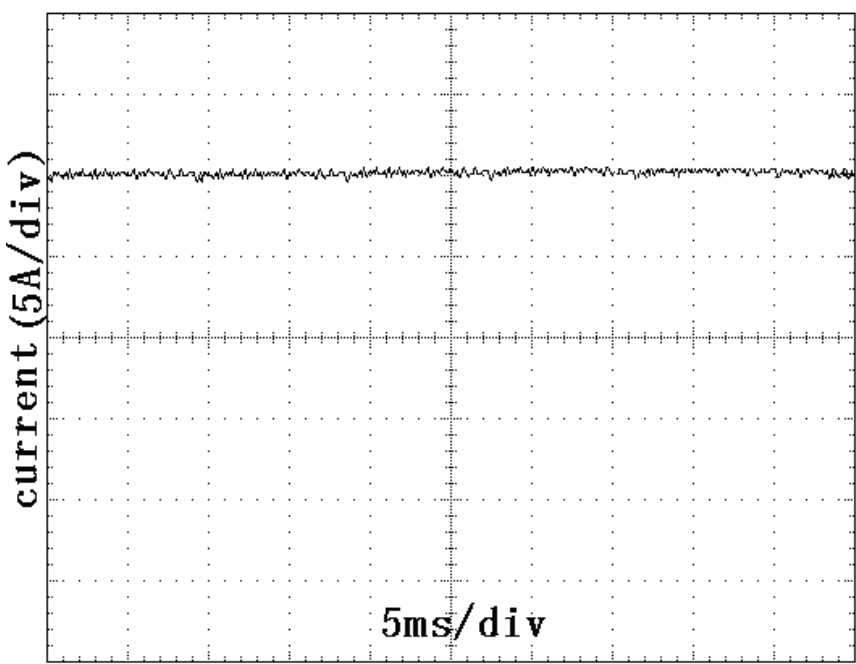

Fig. (10). Waveform of buck circuit's charging current.

Increasing the charge time, the rapid rise of feedback energy is absorbed by the super capacitor. The relationship of MOSFEF voltage and super capacitor voltage is shown in Fig. (11). As can be seen from the diagram, when the super capacitor voltage increases over the limit of protection, after a delay of about $100 \mathrm{~ms}$, the MOSFET gate drive signal changes from high level to low level, and quickly turns off the charging path, effectively protecting the capacitor.

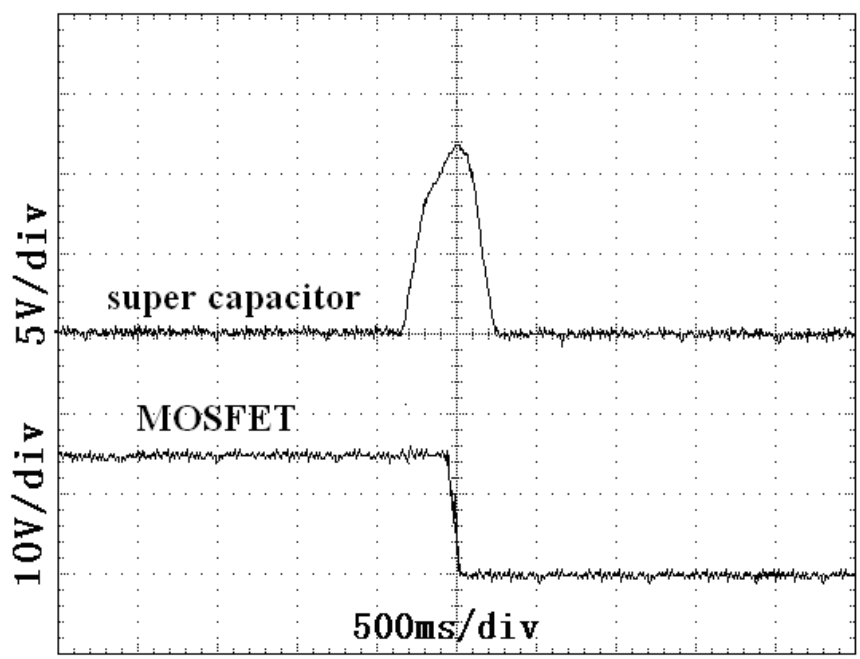

Fig. (11). Waveform of over charge experiment.

\section{CONCLUSION}

1) Composite energy comprising of super capacitor can make the engine avoid working in polluted areas and can effectively improve the dynamic performance of $\mathrm{HEV}$, reducing the pollution in the environment.

2) Composite power with super capacitor can absorb feedback energy effectively in regenerative braking, which greatly improves the utilization of energy . 


\section{CONFLICT OF INTEREST}

The authors confirm that this article content has no conflict of interest.

\section{ACKNOWLEDGEMENTS}

It is a project supported by basic research programs of Suzhou science and Technology Department - industrial application part (SYG201327) and 2012 Innovation Project(QING LAN) of JiangSu Province.

\section{REFERENCES}

[1] Q. Zhang, M. Li, X. S. Wang, and Y. Zhang, "Reinforcement learning in robot path optimization", Journal of Computers, vol.7, pp. 657-662, March 2012.

[2] M. Hassan, N. A. Halvaei, and L. Reza, "New generation of passenger vehicles: FCV or HEV?", ICIT, pp. 452-459, 2006.

[3] M. Mastragostino, and F. Soavi, "Strategies for high-performance supercapacitors for HEV", Journal of Power Sources, vol.174, pp. 89-93, Nov 2007.
[4] S.G. Stewart, V. Srinivasan, and J. Newman, "Modeling the performance of lithium-ion batteries and capacitors during hybridelectric-vehicle operation", Journal of the Electrochemical Society, vol. 155, pp. A664-A671, 2008.

[5] R. Chicurel, "Compromise solution for energy recovery in vehicle braking”, Energy, vol.24, pp.1029-1034, January 1999.

[6] N. Nakzawan, Y. Kono, E. Takao, and N. Takeda, "Development of a braking energy regeneration system for city buses", $S A E$ International, pp.174-186, November 1987

[7] The Evans Capattery, The next generation in double-layer capacitors, Technical Papers, 1989-1994.

[8] A. Kagan, "Cesiwid Maxcap double layer capacitors", Product Information and Application Data, vol. 7, pp. 22-23, 1879.

[9] S.P. Wólsky, N. Marinick, The Fourth International Seminar on Double Layer Capacitors and Similar Energy Storage Devices, Boca Raton, FL, December 12-14, 1994.

[10] M. K. Kazimierczuk, R. C. Cravens, 11, J. Weimer, and S. FriesCarr, "Frequency characterization of super capacitors, 16th Capacitor and Resistor Technology Symposium", New Orleans, LA, pp.11-15, March1996.

[11] J. M. Timmermans, P. Zadora, Y. Cheng, V. Mierlo, and J. Lataire. "Modelling and design of super capacitors as peak power unit for hybrid electric vehicles", Vehicle Power and Propulsion, IEEE Conference September 2005.

(C) Zhang et al.; Licensee Bentham Open.

This is an open access article licensed under the terms of the Creative Commons Attribution Non-Commercial License (http://creativecommons.org/licenses/by-nc/4.0/) which permits unrestricted, non-commercial use, distribution and reproduction in any medium, provided the work is properly cited. 